\title{
DOUBLE RIGHT CORONARY ARTERY: A REPORT OF TWO CASES
}

doi: $10.1590 / \mathrm{S} 1807-59322010000400016$

Yusuf Selcoki, Omer Caglar Yilmaz, Okan Er, Beyhan Eryonucu

\section{INTRODUCTION}

Coronary artery anomalies are usually incidentally diagnosed at the time of coronary angiography or autopsy. In a large series of 70,850 patients undergoing coronary angiography, the incidence of coronary anomalies was found to be $0.24-1.3 \%$. The majority of these were reported to be anomalies of origin or distribution, with separate ostia of the left anterior descending artery and left circumflex artery being the most common. ${ }^{1}$ Although many of the primary congenital coronary anomalies are hemodynamically insignificant, it is important to know the anatomic variants in patients with coronary artery disease who are undergoing either surgical myocardial revascularization or coronary angioplasty. ${ }^{2}$ Double right coronary artery is a very rare coronary abnormality that is generally considered benign.

In this report, we present two cases of double right coronary artery (RCA).

\section{Case Report 1}

A 40-year-old woman was admitted to our center with dyspnea. She had been experiencing shortness of breath and dyspnea on exertion for two months. Her risk factors for coronary artery disease included a history of diabetes mellitus and a family history of premature atherosclerotic heart disease. Her physical examination was unremarkable; cardiac and lung auscultations were normal. Her blood pressure was $125 / 80 \mathrm{mmHg}$ and pulse was 64 beats/min. The chest X-ray was normal. Routine blood and biochemical laboratory tests were nonspecific and nondiagnostic.

The electrocardiogram showed a sinus rhythm with clearly negative $\mathrm{T}$ waves in D2-D3 and aVF. An exercise

Department of Cardiology, Faculty of Medicine, Fatih University - Ankara, Turkey.

Tel.: 903124098888

Email: yussel1971@hotmail.com stress test showed ST-segment depression in the inferior leads at peak exercise, which was asymptomatic. The patient underwent selective left and right coronary artery angiography. The left coronary angiography revealed a normal origin and course of the left main artery (LM), the left circumflex artery (LCx) and the left anterior descending (LAD) arteries. The LCx and LAD arteries were normal. The right coronary angiography revealed two different right coronary arteries arising from a common ostium in the right coronary sinus. Both coursed along the atrioventricular groove and terminated via individual posterior descending arteries (PDA) (Figure 1). Both arteries were free of any angiographically identifiable atherosclerotic lesion.

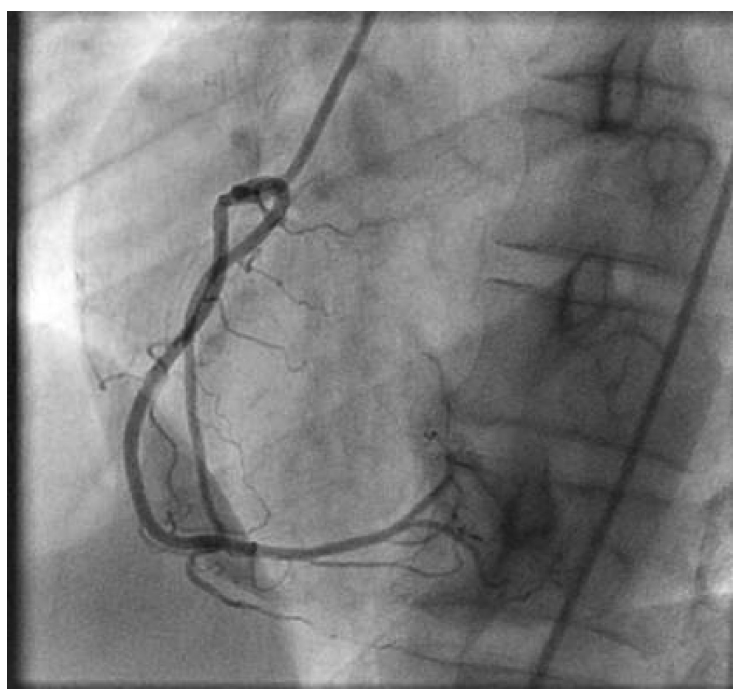

Figure 1 - Left anterior oblique view showing a double right coronary artery.

\section{Case Report 2}

A 66-year-old woman was admitted to our center with chest pain. She was complaining of angina and dyspnea on exertion lasting one week. Her risk factors for coronary artery disease included a history of diabetes mellitus and 
hypertension. The physical examination was completely normal. Cardiac enzymes and troponin- $\mathrm{T}$ were also found to be normal.

The patient underwent selective left and right coronary artery angiography. The left coronary arteries were of normal origin and distribution. The right coronary angiography revealed two separate RCAs originating from a single ostium in the right sinus of Valsalva. Both RCAs gave off branches with typical courses and in parallel distribution (Figure 2). Both arteries were free of any angiographically identifiable atherosclerotic lesion.

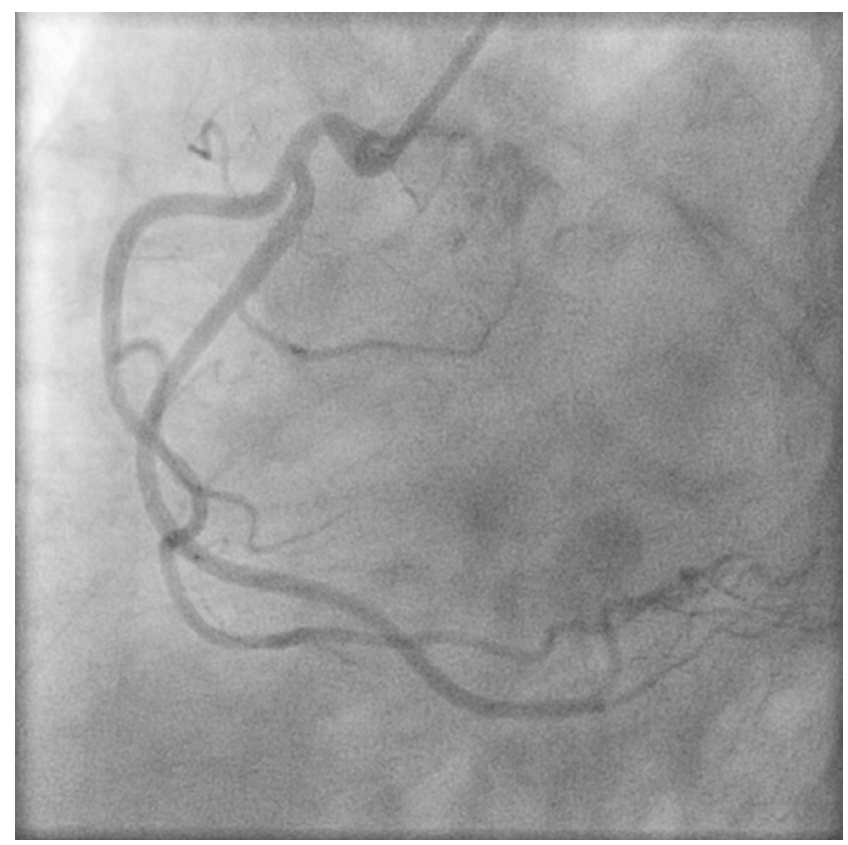

Figure 2 - Selective right coronary angiography (left anterior oblique projection).

\section{DISCUSSION}

Coronary anomalies are incidentally detected during routine coronary angiography. Congenital coronary anomalies are seen in approximately $1 \%$ of adult patients. ${ }^{3}$ Double RCA is a very rare type of coronary abnormality. There was no mention of this anomaly in a series of 126,595 patients who underwent coronary angiography. ${ }^{3}$

The first report about double RCA anomaly in the literature was by Barthe et al. ${ }^{4}$ They observed double RCA originated from one ostium. The vessels were within the right atrioventricular groove. After the origin of a conus artery and a ventricular branch, the most anterior RCA descended toward the acute margin of the heart and terminated in a small posterior descending artery. The second RCA terminated in a small posterior descending and posterolateral branches. In our cases, both right coronary arteries were almost identical in size and both gave rise to a PDA.

The correct diagnosis of double RCA is not easily made based on conventional coronary angiography because it is difficult to distinguish this variation from that of a high takeoff of a large right ventricular branch. This alternative diagnostic possibility creates uncertainty in making the correct diagnosis of double RCA. ${ }^{5}$

Though double RCA is a relatively rare entity, it is not necessarily benign, as it has been associated with atherosclerosis, life-threatening arrhythmia and myocardial infarction. ${ }^{6,7,8}$ However, our patients' coronary arteries were free of atherosclerotic lesions. In the absence of atherosclerotic stenosis, ischemia can be a result of anatomical malformations, including an acute takeoff angle of the anomalous vessel, myocardial squeezing, vasospasm and a small artery. ${ }^{1}$

In these cases, double RCAs were identified as isolated coronary anomalies. Two previous studies have reported double RCA in combination with other anomalies. ${ }^{9,10}$ Double RCA has been reported 18 studies and in 20 cases. ${ }^{11}$ Interestingly, 12 of these cases were identified in the Turkish population. This suggests that certain coronary artery anomalies may be associated with a particular genetic background. The double RCA anomaly is seen mostly in males, as are other congenital coronary anomalies, though our patients were both female. ${ }^{12}$

In conclusion, although double right coronary artery is a rare anomaly, every operator should be familiar with it in order to perform an adequate examination.

\section{REFERENCES}

1. Tuncer C, Batyraliev T, Yılmaz R, Gökçe M, Eryonucu B, Köroğlu S. Origin and distribution anomalies of the left anterior descending artery in 70,850 adult patients: multicenter data collection. Catheter Cardiovasc Interv 2006; 68: 574-85.

2. Erbagcı H, Davutoglu V, Turkmen S, Kizilkan N, Gumusburun E. Double right coronary artery: review of literature. Int. J. of Cardiovascular Imaging 2006;22:9-11.
3. Yamanaka O, Hobbs RE. Coronary artery anomalies in 126,595 patients undergoing coronary arteriography. Cathet Cardiovasc Diagn. 1990;21:28-40.

4. Barthe JE, Benito M, Sala J, Houbani AJ, Quintana E, Esplugas E, Gausi C, et al. Double right coronary artery. Am J Cardiol. 1994;73:622. 
5. Altun A, Akdemir O, Erdogan O, Ozbay G. An interesting diagnostic dilemma: double right coronary artery or high take off of a large right ventricular branch. Int J Cardiol. 2002;82:99-102.

6. Timurkaynak T, Ciftci H, Cengel A. Double right coronary artery with atherosclerosis: A rare coronary artery anomaly. J Invasive Cardiol. 2002;14:337-9.

7. Ozeren A, Aydin M, Bilge M, Dursun A, Onuk T. Atherosclerotic double right coronary artery and ectasia of left coronary arteries in a patient with presented acute coronary syndrome and ventricular tachycardia. Int J Cardiol. 2005;102:341-3.

8. Rohit M, Bagga S, Talwar KK. Double right coronary artery with acute inferior wall myocardial infarction. J Invasive Cardiology. 2008;20:3740.
9. Young Hyman PJ, Tommaso CL, Singleton RT. A new double coronary artery : the right coronary artery originating above the coronary sinus giving off the circumflex artery. J Am Coll Cardiol. 1984;4:1329-31.

10. Garg N, Goel PK, Sinha N. Double right coronary artery with anomalous. Indian Heart J. 2002;54:428-31.

11. Sarı I, Davutoğlu V, Aksoy M. The correct number of double right coronary artery reported in the literature. Int J Cardiol. 2008;130:283-4.

12. Misuraca L, Rutigliano D, Pestrichella V, Contegiacomo G, Balbarini A. A very rare congenital abnormality: double right coronary artery. A case report. J Cardiovascular Medicine. 2009;10:643-5. 